\title{
The impact of polymorphism in PNPLA3 and TM6SF2 genes on the susceptibility and survival of hepatitis C-related Hepatocellular carcinoma
}

\section{Samar Samir Youssef ( $\nabla$ samaryoussef67@gmail.com )}

National Research Centre, Cairo, Egypt

\section{Eman Abd El Razek Abbas}

National Research Centre, Cairo, Egypt

Asmaa M. Elfiky

National Research Centre, Cairo, Egypt

\section{Sameh Seif}

National Hepatology and Tropical Medicine Research Institute, Cairo, Egypt

\section{Mohamed Mahmoud Nabeel}

Endemic medicine and Hepato-gastroenterology Department, Faculty of Medicine, Cairo University, Cairo, Egypt

Hend Ibrahim Shousha

Endemic medicine and Hepato-gastroenterology Department, Faculty of Medicine, Cairo University, Cairo, Egypt

\section{Ashraf Omar Abdelaziz}

Endemic medicine and Hepato-gastroenterology Department, Faculty of Medicine, Cairo University, Cairo, Egypt

\section{Research Article}

Keywords: hepatocellular carcinoma (HCC), PNPLA3, TM6SF2, Single Nucleotide polymorphism, chronic hepatitis C

Posted Date: May 5th, 2021

DOI: https://doi.org/10.21203/rs.3.rs-493299/v1

License: (c) (1) This work is licensed under a Creative Commons Attribution 4.0 International License. Read Full License 


\section{Clinical and Experimental Medicine}

\section{The impact of polymorphism in PNPLA3 and TM6SF2 genes on the susceptibility and survival of hepatitis C-related Hepatocellular carcinoma \\ --Manuscript Draft--}

Manuscript Number:

Full Title:

Article Type:

Keywords:

Corresponding Author:
CLEM-D-21-00350

The impact of polymorphism in PNPLA3 and TM6SF2 genes on the susceptibility and survival of hepatitis C-related Hepatocellular carcinoma

\section{Original Article}

hepatocellular carcinoma (HCC), PNPLA3, TM6SF2, Single Nucleotide polymorphism, chronic hepatitis C

Samar Youssef

National Research Centre

Cairo, EGYPT

\section{Corresponding Author Secondary}

Information:

Corresponding Author's Institution:

National Research Centre

\section{Corresponding Author's Secondary} Institution:

\section{First Author:}

Samar Youssef

First Author Secondary Information:

Order of Authors:

Samar Youssef

Eman Abbas

Asmaa Elfiky

Sameh Seif

Mohamed Nabeel

Hend Shousha

Ashraf Abdelaziz

Order of Authors Secondary Information:

Funding Information:

\section{Abstract:}

Background: Genetic variants of Patatin-like phospholipase domain-containing protein 3 (PNPLA3) and transmembrane 6 superfamily member 2 (TM6SF2) genes have been reported with development of hepatocellular carcinoma (HCC). Aim: To explore the role of The PNPLA3 rs738409 and TM6SF2 rs58542926 single nucleotide polymorphisms (SNPs) on the incidence and survival of HCV induced HCC in Egyptians. Method: This case-control study included (120) HCC and (144) Hepatitis $\mathrm{C}$ virus (HCV) patients. Baseline clinical, laboratory, tumor characteristics data, HCC recurrence, and overall survival were collected. PNPLA3 rs738409 and TM6SF2 rs58542926 polymorphism were detected by TaqMan allelic discrimination assay. Results: HCC Patients were significantly older with male predominance. A significant difference between TT genotype of TM6SF2 frequency was observed in HCC compared with HCV patients. Moreover, T allele of TM6SF2 distributions revealed significant contribution with different stages of $\mathrm{HCC}(p=0.03)$. Both PNPLA3 rs738409 and TM6SF2 rs58542926 variants showed significant relation with treatment response according to the modified RECIST criteria. Age and diabetes mellitus were the independent factors associated with the development of $\mathrm{HCC}$ by multivariate regression analysis. Diabetes, BCLC stage, performance status and response to treatment were significantly associated with patients' survival. Conclusion : TM6SF2 rs58542926 polymorphism not PNPLA3 rs738409 could be implicated in the development $\mathrm{HCV}$ induced $\mathrm{HCC}$ and its progression. 
Andrea Savarino

ISS: Istituto Superiore Di Sanita, Italy

andrea.savarino@iss.it

Ming-Sheng Huang

Sun Yat-sen University, China

huangmsh@mail.sysu.edu.cn

Qu Lin

Guangdong Key Laboratory of Liver Disease Research, The Third Afliated Hospital of Sun Yat-sen University, Guangzhou 510630, China

Linqu@mail.sysu.edu.cn 
The impact of polymorphism in PNPLA3 and TM6SF2 genes on the susceptibility and survival of hepatitis Crelated Hepatocellular carcinoma

Samar Samir Youssef ${ }^{1 *}$, Eman Abd El Razek Abbas ${ }^{1}$, Asmaa M. Elfiky ${ }^{2}$,Sameh Seif ${ }^{3}$, Mohamed

Mahmoud Nabeel ${ }^{4}$, Hend Ibrahim Shousha ${ }^{4}$, Ashraf Omar Abdelaziz ${ }^{4}$

${ }^{1}$ Microbial Biotechnology Department, Genetic Engineering and Biotechnology Division, National Research

Centre, Cairo, Egypt

${ }^{2}$ Environmental and Occupational Medicine Department, Environmental Research Division, National Research

Centre, Cairo, Egypt

${ }^{3}$ National Hepatology and Tropical Medicine Research Institute, Cairo, Egypt

${ }^{4}$ Endemic medicine and Hepato-gastroenterology Department, Faculty of Medicine, Cairo University, Cairo, Egypt

*Corresponding author: E-mail: samaryoussef67@gmail.com (Samar Samir Youssef) 


\begin{abstract}
Background: Genetic variants of Patatin-like phospholipase domain-containing protein 3 (PNPLA3) and transmembrane 6 superfamily member 2 (TM6SF2) genes have been reported with development of hepatocellular carcinoma (HCC). Aim: To explore the role of The PNPLA3 rs738409 and TM6SF2 rs58542926 single nucleotide polymorphisms (SNPs) on the incidence and survival of HCV induced HCC in Egyptians. Method: This casecontrol study included (120) HCC and (144) Hepatitis C virus (HCV) patients. Baseline clinical, laboratory, tumor characteristics data, HCC recurrence, and overall survival were collected. PNPLA3 rs738409 and TM6SF2 rs58542926 polymorphism were detected by TaqMan allelic discrimination assay. Results: HCC Patients were significantly older with male predominance. A significant difference between TT genotype of TM6SF2 frequency was observed in HCC compared with HCV patients. Moreover, T allele of TM6SF2 distributions revealed significant contribution with different stages of HCC ( $p=0.03)$. Both PNPLA3 rs738409 and TM6SF2 rs58542926 variants showed significant relation with treatment response according to the modified RECIST criteria. Age and diabetes mellitus were the independent factors associated with the development of HCC by multivariate regression analysis. Diabetes, BCLC stage, performance status and response to treatment were significantly associated with patients' survival. Conclusion: TM6SF2 rs58542926 polymorphism not PNPLA3 rs738409 could be implicated in the development HCV induced HCC and its progression.
\end{abstract}

Keywords: hepatocellular carcinoma (HCC), PNPLA3, TM6SF2, Single Nucleotide polymorphism, chronic hepatitis $\mathrm{C}$ 


\section{Introduction}

Hepatocellular carcinoma (HCC) classifies the sixth most common type of malignancy worldwide [1]. The prevalence of HCC diverges by geographic region according to its epidemiological data. In Egypt, liver cancer is ranked the $3^{\text {rd }}$ and $15^{\text {th }}$ in Africa and worldwide, respectively and is the most common cause of mortality and morbidity-related cancer [2]

Environment-related risk factors such as both hepatitis B virus (HBV) and hepatitis $\mathrm{C}$ virus(HCV) and other predisposing factors including non-alcoholic fatty liver disease (NAFLD), diabetes, obesity, and smoking are associated with increased HCC risk by approximately 20 fold [3] [4]. It was also confirmed that genetic mutations affect the susceptibility of liver cancer [5]. Genetic factors are related to the pathogenesis of liver cancer, and these factors increase the differences between individuals in the susceptibility to diseases $[5,6]$.

Patatin-like phospholipase domain-containing protein 3 (PNPLA3), adiponutrin, is a multifunction enzyme encoded by PNPLA3gene and is located on chromosome 22 [7]. It is highly expressed in liver and adipose tissue and also, it contributes to carbohydrate and lipid metabolism in the liver [8].

Recently, several studies have revealed that there is an association between altered PNPLA3 expression and multiple chronic liver diseases such as alcoholic liver disease and non-alcoholic fatty liver disease [9, 10]

In genome-wide association (GWA) studies, The PNPLA3 SNP, rs738409 C > G (Ile148Met), was reported in human. This variant was associated with the development of NAFLD [11, 12]. Recent studies have demonstrated an important role of rs738409 SNP in liver cancer risk [13, 14]. Patients carrying mutant homozygote $\mathrm{G}$ allele had elevated hepatic triglyceride level and increased serum ALT levels[15]. Also, PNPLA3 (rs738409: C> G) may affect the severity of fibrosis in patients with fatty liver [16, 17]. These last findings could stimulate hepatocarcinogenesis through dysregulation in lipid metabolism and inflammatory mediators [18].

Another important gene polymorphism that has a significant role in lipid metabolism and chronic liver disease is transmembrane 6 superfamily member 2 (TM6SF2) gene which is located on chromosome 19. A study revealed that a significant association was found between TM6SF2 rs58542926 and NAFLD [12]. Also, Musso, Cipolla [19] have shown that the TM6SF2 variant had a significant effect on nutrient oxidation, glucose and lipid metabolism in NAFLD patients. Another study in obese children found that TM6SF2 (c.499A> G) was significant 
association with lower levels of total cholesterol and low-density lipoprotein cholesterol, indicating that it could enhance liver injury[20].

This study aimed to investigate the relationship between the PNPLA3 rs738409 and TM6SF2 rs58542926 polymorphisms and hepatitis C-induced HCC occurrence, recurrence and survival.

\section{Subjects and methods}

\section{Subjects}

A total 264 subjects were recruited in this study including (120) who had HCC and (144) patients infected with chronic hepatitis C (CHC) genotype 4. HCC Patients were recruited from the Multidisciplinary HCC clinic, Kasr Alainy hospital, Cairo University, Egypt.While HCV patients were enrolled from the National Hepatology and Tropical Medicine Research Institute (NHTMRI), Cairo, Egypt.

HCC was diagnosed according to the criteria in the guidelines of the American Association for the study of Liver Diseases (AASLD), using computerized tomography (CT) or magnetic resonance imaging (MRI) techniques and alpha-fetoprotein (AFP) [21]. Inclusion criteria for all patients was: (i) lack of co-infection with HBV, HIV, EBV and CMV, (ii) no history of alcohol consumption, (iii) no bilharzias and,(iv) no suffering from other autoimmune or hematological diseases. HCC patients were treatment naïve.

Patients were subjected to the following: Full history taking and clinical assessment. Baseline laboratory tests were collected in the form of complete blood count, liver function tests, renal functions, Alpha-fetoprotein (AFP) measurement in addition to tumor characteristics (focal lesion site, size and number, portal vein and abdominal lymph node assessment). HCV infection was diagnosed using a Quantitative real-time polymerase chain reaction (PCR) for HCV RNA (Cobas Amplicor, HCV Roche, Branchburg, NJ, USA, v 2.0, detection limit 15 $\mathrm{IU} / \mathrm{mL})$.

HCC patients were assessed by Eastern Cooperative Oncology Group performance status (PS) [22] and managed according to the Barcelona Clinic Liver Cancer (BCLC) guideline [23]. Response to treatment was rated using the modified Response Evaluation Criteria in Solid Tumors (mRECIST) guidelines[24]. 
Follow-up: The initial evaluation of HCC treatment response was done after 1 month by Triphasic CT or MRI then every 3 months for 2 years and then return to routine surveillance every 6 months. Follow-up was performed till patients' death or till the end of the study [25]

\section{Blood sample and DNA isolation}

A 5-ml blood sample was collected from each individual in sterile anticoagulant tubes. The extraction and purification of genomic DNA from the peripheral blood lymphocytes were conducted using a QIAamp DNA Mini and Blood Mini kit (Qiagen \#51104) according to the manufacturer's instructions and preserved at $-80{ }^{\circ} \mathrm{C}$ for genetic determinations.

\section{Genotyping of PNPLA3 rs738409 and TMS6F2 rs58542926 SNPs}

After DNA extraction, the samples of all patients were subjected to the real-time PCR reaction to analyse the polymorphism of the two genes and the initial step was to bring the concentration of DNA of each sample to 20 ng/ $\mu 1$. So, samples were diluted to reach this value. Then genotyping of PNPLA3 rs738409 and TMS6F2 rs58542926 were performed for all patients by real-time PCR and using the system "Taqman allelic discrimination assay" on Agilent Mx3000p qPCR, real-time PCR (Agilent Technologies, Germany). The assay was standardized in a final volume of $25 \mu \mathrm{l}: 12.5 \mu \mathrm{l}$ of $2 \mathrm{X}$ TaqMan Universal MasterMix II, no UNG (Applied Biosystems, USA), 1.25 $\mu \mathrm{l}$ of Genotyping Assay 20X, $10.25 \mu \mathrm{l}$ of Dnase free water (Promega, USA) and $1 \mu \mathrm{l}$ of genomic DNA. The cycling was as follows: $95{ }^{\circ} \mathrm{C}$ for $10 \mathrm{~min}$, followed by 40 cycles of $95{ }^{\circ} \mathrm{C}$ for $15 \mathrm{~s}$ and $60{ }^{\circ} \mathrm{C}$ for $1 \mathrm{~min}$. The interpretation of genotypes for PNPLA3 rs738409 and TMS6F2 rs58542926 was given by (CC, CG, GG and CC, CT, TT respectively).

\section{Statistical analysis}

All statistical analyses were performed using the SPSS program for Windows (version 20 statistical software; Texas instruments, IL, USA). Categorical variables are given as the number and percentage. Continuous data are expressed as the mean and standard deviation or as Median with the interquartile range $(25 \%-75 \%)$. Comparison between distributions of categorical variables was performed using Chisquare $\left(\mathrm{X}^{2}\right)$ test. In addition, variables were described as odds ratio (OR) with $95 \%$ confidence interval $(95 \% \mathrm{CI})$ where appropriate. The data were considered significant $\mathrm{t}$ if the $p$ value was $<0.05$ and highly significant if $p<0.01$. The associations between 
the genes polymorphisms and HCC stages were tested using the crosstabs test. Kaplan-Meier method was used to calculate the survival rates and the log-rank test was used to test the significance in the difference in the patients' survival.

\section{Results}

\section{Characteristics of the studied patients}

A total of 264 subjects were analyzed in our study, including 120 patients with HCC, 144 patients with Hepatitis $\mathrm{C}$ virus (HCV) but without HCC. The characteristics of all the patients are described in (Table 1). Patients with HCC $(n=120)$ were significantly older with male predominance. They had significantly higher serum total bilirubin, AFP and lower hemoglobin, platelet count, serum albumin and alanine aminotransaminase (ALT).

\section{Association of PNPLA3 rs738409 and TMS6F2 rs58542926 variants with HCC}

We examined if the frequencies of SNPs were associated with HCC development in patients with HCVrelated HCC (Table 2). Our data showed that the frequencies of PNPLA3 GG, CG, GG genotypes did not differ significantly between HCV and HCC patients. On the contrary, the frequencies of TM6SF2 TT genotype was significantly higher in HCC compared with HCV patients (Table 2), indicating a role of this genotype in HCC development.

\section{Association of PNPLA3 rs738409 and TMS6F2 rs58542926 variant with HCC characteristics, staging and response to treatment}

We investigated the association between polymorphisms at PNPLA3 rs738409, TM6SF2 rs58542926 and HCC clinical characteristics (Table 3), but there was no significant correlation between the two polymorphisms and any of the patients and tumor characteristics. On the contrary, we observed a significant $(P=0.03)$ association between TM6SF2 rs58542926 polymorphism and disease stage with higher frequency of TM6SF2 T allele in late stage HCC patients $(0.313 \%)$ compared to early and intermediate stages $(0.17 \%)$ patients (Table 3$)$. The BCLC staging did not show significant difference in genotype and allele distribution of PNPLA3 rs738409, although there was a significant higher frequency of the GG genotype and the $\mathrm{G}$ allele in advanced stage compared to the $\mathrm{CC}$ genotype and the $\mathrm{C}$ allele respectively (Table 4). 


\section{Analysis of risk factors associated with HCC in the studied individuals:}

We assessed risk factors for HCC in the studied population, which showed that age, male gender, smoking, AFP, and diabetes were statistically significant risk factor in univariate analysis. But only age and diabetes mellitus were the independent factors associated with the development of HCC by multivariate regression analysis.

\section{Correlation of the SNPs with HCC survival:}

We examined the impact of different factors including the studied polymorphisms on HCC survival in the studied patients (Table 6). Results showed that only Diabetes, HCC stage, performance status, response to mRECIST were significantly associated with patient's survival(fig 1), while polymorphism in PNPLA3 rs738409 and TM6SF2 rs58542926 does not have significant relation with survival, and similarly was age, gender, smoking, CHILD score and liver stiffness (Figure. 1) 


\section{Discussion}

To the best of our knowledge, so far this is the first study investigating the correlation between PNPLA3 rs738409 and TM6SF2 rs58542926 polymorphism and HCC in Egyptian HCV induced HCC patients.

In Egypt, HCC is the fourth common cancer [26] and Mounting incidence of HCC have been recorded based on hospital studies [27], [28-30] and it is considered the most common cause for mortality and morbidity in Egypt [31].

It has been demonstrated that host genetic factors, such as single nucleotide polymorphisms (SNPs), could affect individual susceptibility to HCC[32]. In this study we explored the correlation between polymorphisms at PNPLA3 rs738409 and TM6SF2 rs58542926 and HCC in Egyptian patients who had HCV infection as the only etiological factor for HCC.

Single nucleotide polymorphism rs738409 in PNPLA3 is nowadays considered one of the genetic factors with an important impact on progression of several liver diseases of different etiology [33]. A met-analysis on Western populations showed that the SNP was associated with increased risk of HCC in patients with ALD and NAFLD [33, 34]. In Asia, it was recently reported also that this polymorphism was linked to fibrosis progression and liver carcinogenesis in patients with NAFLD [17, 35]. In patients with HCV infection, PNPLA3 rs738409 polymorphism might be involved in liver steatosis and fibrosis but its association with development of $\mathrm{HCC}$ was less clear with conflicting results [33, 34, $36,37]$

Our results showed that PNPLA3 rs738409 polymorphism didn't show an association with HCC development, this is controversial with Yang, Trepo [38] and Ezzikouri, Alaoui [39] who showed an association between the PNPLA3 GG genotype and an increased risk of HCC development and showed that patients with PNPLA3 GG genotype had 3fold increased risk when compared to PNPLA3 CC genotype in patients with mild chronic hepatitis $\mathrm{C}$. This is very interesting conflict as PNPLA3 rs738409 is known to exhibit ethnic diversity in its frequency [11, 40], so we expected similar results with Ezzikouri and colleagues, 2014 study on Moroccan patients with similar Arabic ethnicity but this wasn't the case and this may be attributed to the fact that Moroccan populations are mixed Berberic and Arabic ethnicity, and that they reported a higher frequency (28\%) of the risk GG genotype compared with only $12.5 \%$ in our Egyptian patients. Interestingly, on the contrary, our results agreed with results from Thai patients [31] who showed a PNPLA3 
rs 738409 GG frequency of $10.7 \%$ which is very similar to ours (12.5\%) and showed this polymorphism is not linked to HCV induced HCC. Our results are also in line with that of $[41,42]$ representing mixed American plus European and Japanese races ,respectively who proved that PNPLA3 is not a significant risk factor for HCC among patients with $\mathrm{HCV}$.

TM6SF2, mainly expressed in the liver, kidney and gut tissue, is responsible for hepatic lipid metabolism by modulating triglyceride secretion and increased intracellular lipid droplet concentration [43]. Polymorphism in TM6SF2 rs58542926 causes decreased protein expression, which is associated with higher intrahepatic triglyceride content and lower very low-density lipoprotein secretion [12]. The correlation between polymorphism in TM6SF2 gene and the risk of liver cancer attracted many researcher's attention and results vary from study to the other.

Similar to PNPLA3 rs738409, TM6SF2 rs58542926 is contributable to the progressive liver disease not only NAFLD but also ALD, extending from steatosis to progressive fibrosis and cirrhosis [44]. On the contrary, our previous study showed that there wasn't a correlation between TM6SF2 rs58542926 polymorphism and fibrosis progression in Egyptian HCV patients [45]. Recent reports from European Caucasian populations demonstrated that TM6SF2 T allele might be a potential genetic risk factor for developing HCC in patients with NAFLD and ALD [46]. Another study in Thai individuals showed that this variant was independently linked to non-Hepatitis B non-Hepatitis C (NBNC)-HCC but not viral induced HCC [31]. Results from a recent met-analysis showed that the risk of liver cancer in the TT genotype group was significantly higher than that of the CC + CT genotype group [47].

It is unclear whether TM6SF2 rs58542926 increases the risk of HCC in HCV patients, and studies exploring this correlation are extremely few. Yang et al., Confirmed for the first time in a prospective manner the link between TM6SF2 rs58542926 and HCC occurrence in cohort of alcohol related cirrhosis, but not associated with HCC development in HCV-related cirrhosis [38]. Our data are contradictory with Yang et al; as our results showed a correlation between carrying the TT risk genotype and development of HCC in Egyptian HCV induced HCC patients. This difference may be attributed to different ethnicity in addition to different HCV genotype. Indeed, further studies dissecting this correlation between TM6SF2 rs58542926 and HCV induced HCC are urgently needed from different ethnicities and HCV genotypes in order to be able to figure a scenario for this correlation. Consequently, genotyping of this polymorphism will allow more precise HCC risk-stratification of patients with chronic liver diseases, and genotypeguided screening algorithms would optimize patient care [14]. 
Regarding results of the correlation of these SNPs with clinical characteristics and the prognostic significance in our study, we found that PNPLA3 GG genotype had more advanced tumor stages than non GG genotype patients indicating a prognostic role of this polymorphism in the studied patients, this is concordant with an Italian study which reported that patients with ALD- and NAFLD-related HCC harboring PNPLA3 GG genotype had more advanced tumor stages at presentation and worse survival compared with individuals with non-GG genotype [48]. Similarly, we found a significant correlation between HCC stages and T allele of TM6SF2 rs58542926 pointing the prognostic importance of this polymorphism also in HCV induced HCC Egyptian patients and this is a unique finding to our study we did not reach mimicking finding in other studies. In contrast to our results, [38] did not identify any significant association between PNPLA3 rs738409, TM6SF2 rs58542926 and histological features of the tumor. Moreover, also [31] reported that the correlation of these SNPs with clinical characteristics and the prognostic significance was not observed in his cohort.

In this study we investigated also the correlation between PNPLA3 rs738409, TM6SF2 rs58542926 polymorphisms and survival of HCC patients studied and we couldn't show a correlation between them. This is in line with the study of [31]

\section{Conclusion}

our finding indicates that PNPLA3 and TM6SF2 variants might influence HCC development in this group of HCV induced HCC Egyptian patients, suggesting differential mechanisms of liver carcinogenesis in relation to the underlying etiologies of liver disease and suggesting to consider the role of the hepatitis $\mathrm{C}$ genotype, in addition to emphasizing the importance of genotyping of these polymorphisms in $\mathrm{HCV}$ risk patients for earlier detection and better management of HCC.

\section{Acknowledgement}

The authors would like to acknowledge the National Research Centre, as well as National Hepatology and Tropical Medicine Research Institute, Cairo, Egypt, and Endemic medicine and Hepato-gastroenterology Department, Faculty of Medicine, Cairo University, Cairo, Egypt, for providing laboratory space, types of equipment, and patient samples for achievement of the current work

\section{Disclosure statement}


Authors declare that they have no conflict of interest regarding the publication of this paper.

\section{Ethical approval}

This work was carried out following the Code of Ethics of the World Medical Association (Declaration of Helsinki) for experiments 1975 and its later amendments. The study protocol was approved by the ethical committee of the faculty of medicine, Cairo University number (N-51-2018).

\section{Consent to participate}

All patients signed a written informed consent before inclusion in the study.

\section{Funding}

This research did not receive any specific grant from funding agencies in the public, commercial, or not-for-profit sectors.

\section{Availability of data}

The authors confirm that the data supporting the findings of this study are available within the article.

\section{Author contributions}

All the authors have accepted responsibility for the entire content of this submitted manuscript and approved submission

\section{References}

1. Forner A, Reig M, Bruix J. Hepatocellular carcinoma. The Lancet. 2018;391:1301-14.

2. Rashed WM, Kandeil MAM, Mahmoud MO, Ezzat S. Hepatocellular Carcinoma (HCC) in Egypt: A comprehensive overview. Journal of the Egyptian National Cancer Institute. 2020;32:1-11.

3. Liver EAFTSOT. EASL-EORTC clinical practice guidelines: management of hepatocellular carcinoma. Journal of hepatology. 2012;56:908-43.

4. Koh S, Tan AT, Li L, Bertoletti A. Targeted therapy of hepatitis B virus-related hepatocellular carcinoma: present and future. Diseases. 2016;4:10.

5. Nahon P, Zucman-Rossi J. Single nucleotide polymorphisms and risk of hepatocellular carcinoma in cirrhosis. Journal of Hepatology. 2012;57:663-74.

6. Li J-f, Zheng E-q, Xie M. Association between rs738409 polymorphism in patatin-like phospholipase domain-containing protein 3 (PNPLA3) gene and hepatocellular carcinoma susceptibility: Evidence from case-control studies. Gene. 2019;685:143-8.

7. Collins JE, Goward ME, Cole CG, et al. Reevaluating human gene annotation: a second-generation analysis of chromosome 22. Genome research. 2003;13:27-36. 

like phospholipase family. Journal of lipid research. 2006;47:1940-9.

9. Trépo E, Romeo S, Zucman-Rossi J, Nahon P. PNPLA3 gene in liver diseases. Journal of hepatology. 2016;65:399-412.

10. Trepo E. Contribution of PNPLA3 gene to the natural history of liver diseases. Acta gastro-enterologica Belgica. 2017;80:43-51.

11. Romeo S, Kozlitina J, Xing C, et al. Genetic variation in PNPLA3 confers susceptibility to nonalcoholic fatty liver disease. Nature Genetics. 2008;40:1461-5.

12. Kozlitina J, Smagris E, Stender S, et al. Exome-wide association study identifies a TM6SF2 variant that confers susceptibility to nonalcoholic fatty liver disease. Nature genetics. 2014;46:352-6.

13. Hassan MM, Kaseb A, Etzel CJ, et al. Genetic variation in the PNPLA3 gene and hepatocellular carcinoma in USA: risk and prognosis prediction. Molecular carcinogenesis. 2013;52:139-47.

14. Stickel F, Buch S, Nischalke HD, et al. Genetic variants in PNPLA3 and TM6SF2 predispose to the development of hepatocellular carcinoma in individuals with alcohol-related cirrhosis. American Journal of Gastroenterology. 2018;113:1475-83.

15. Yuan X, Waterworth D, Perry JR, et al. Population-based genome-wide association studies reveal six loci influencing plasma levels of liver enzymes. The American Journal of Human Genetics. 2008;83:520-8.

16. Valenti L, Al-Serri A, Daly AK, et al. Homozygosity for the patatin-like phospholipase-3/adiponutrin 1148M polymorphism influences liver fibrosis in patients with nonalcoholic fatty liver disease. Hepatology. 2010;51:1209-17.

17. Seko Y, Sumida Y, Tanaka S, et al. Development of hepatocellular carcinoma in Japanese patients with biopsy-proven non-alcoholic fatty liver disease: association between PNPLA3 genotype and hepatocarcinogenesis/fibrosis progression. Hepatology Research. 2017;47:1083-92.

18. Takeuchi Y, Ikeda F, Moritou Y, et al. The impact of patatin-like phospholipase domain-containing protein 3 polymorphism on hepatocellular carcinoma prognosis. Journal of gastroenterology. 2013;48:40512.

19. Musso G, Cipolla U, Cassader M, et al. TM6SF2 rs58542926 variant affects postprandial lipoprotein metabolism and glucose homeostasis in NAFLD. Journal of lipid research. 2017;58:1221-9.

20. Grandone A, Cozzolino D, Marzuillo P, et al. TM6SF2 G lu167 L ys polymorphism is associated with low levels of LDL-cholesterol and increased liver injury in obese children. Pediatric obesity. 2016;11:115-9. 21. Galle PR, Foerster F, Kudo M, et al. Biology and significance of alpha-fetoprotein in hepatocellular carcinoma. Liver international. 2019;39:2214-29.

22. Hsu CY, Lee YH, Hsia CY, Huang YH, Su CW, Lin HC, et al. Performance status in patients with hepatocellular carcinoma: determinants, prognostic impact, and ability to improve the Barcelona Clinic Liver Cancer system. Hepatology. 2013;57:112-9.

23. Liver EAftSot. Electronic address eee, European Association for the Study of the L (2018) EASL clinical practice guidelines: management of hepatocellular carcinoma. J Hepatol https://doi org/101016/j jhep. 2018;19.

24. Lencioni R, Llovet JM. Modified RECIST (mRECIST) assessment for hepatocellular carcinoma. Seminars in liver disease: (C) Thieme Medical Publishers; 2010. p. 052-60. 25. Verslype C, Rosmorduc O, Rougier P. Group EGW (2012) Hepatocellular carcinoma: ESMO-ESDO Clinical Practice Guidelines for diagnosis, treatment and follow-up. Ann Oncol.23.

26. Akinyemiju T, Abera S, Ahmed M, et al. The burden of primary liver cancer and underlying etiologies from 1990 to 2015 at the global, regional, and national level: results from the global burden of disease study 2015. JAMA oncology. 2017;3:1683-91.

27. El-Zayadi A-R, Badran HM, Barakat EM, et al. Hepatocellular carcinoma in Egypt: a single center study over a decade. World journal of gastroenterology: WJG. 2005;11:5193. 
28. Abd-Elsalam S, Elwan N, Soliman H, et al. Epidemiology of liver cancer in Nile delta over a decade: a single-center study. South Asian journal of cancer. 2018;7:24.

29. Ezzat S, Abdel-Hamid M, Eissa SA-L, et al. Associations of pesticides, HCV, HBV, and hepatocellular carcinoma in Egypt. International journal of hygiene and environmental health. 2005;208:329-39. 30. Ziada DH, El Sadany S, Soliman H, et al. Prevalence of hepatocellular carcinoma in chronic hepatitis C patients in Mid Delta, Egypt: A single center study. Journal of the Egyptian National Cancer Institute. 2016;28:257-62.

31. Raksayot M, Chuaypen N, Khlaiphuengsin A, et al. Independent and additive effects of PNPLA3 and TM6SF2 polymorphisms on the development of non-B, non-C hepatocellular carcinoma. J Gastroenterol. 2019;54:427-36.

32. Dragani TA. Risk of HCC: genetic heterogeneity and complex genetics. Journal of hepatology. 2010;52:252-7.

33. Singal AG, Manjunath $H$, Yopp AC, et al. The effect of PNPLA3 on fibrosis progression and development of hepatocellular carcinoma: a meta-analysis. 2014;109:325.

34. Trépo E, Nahon P, Bontempi G, et al. Association between the PNPLA3 (rs738409 C> G) variant and hepatocellular carcinoma: evidence from a meta-analysis of individual participant data. Hepatology. 2014;59:2170-7.

35. Ueyama M, Nishida N, Korenaga M, et al. The impact of PNPLA3 and JAZF1 on hepatocellular carcinoma in non-viral hepatitis patients with type 2 diabetes mellitus. Journal of gastroenterology. 2016;51:370-9. 36. Khlaiphuengsin A, Kiatbumrung R, Payungporn S, Pinjaroen N, Tangkijvanich P. Association of PNPLA3 polymorphism with hepatocellular carcinoma development and prognosis in viral and non-viral chronic liver diseases. Asian Pacific Journal of Cancer Prevention. 2016;16:8377-82.

37. Youssef SS, Abbas EAER, Youness RA, Elemeery MN, Nasr AS, Seif S. PNPLA3 and IL 28B signature for predicting susceptibility to chronic hepatitis $C$ infection and fibrosis progression. Archives of physiology and biochemistry. 2019:1-7.

38. Yang J, Trepo E, Nahon P, et al. PNPLA3 and TM6SF2 variants as risk factors of hepatocellular carcinoma across various etiologies and severity of underlying liver diseases. Int J Cancer. 2019;144:533-44.

39. Ezzikouri S, Alaoui R, Tazi S, et al. The adiponutrin I148M variant is a risk factor for HCV-associated liver cancer in North-African patients. Infection, Genetics and Evolution. 2014;21:179-83.

40. Fan J-G, Kim S-U, Wong VW-S. New trends on obesity and NAFLD in Asia. Journal of hepatology. 2017;67:862-73.

41. Ali M, Yopp A, Gopal P, et al. A Variant in PNPLA3 Associated With Fibrosis Progression but not Hepatocellular Carcinoma in Patients With Hepatitis C Virus Infection. Clin Gastroenterol Hepatol. 2016;14:295-300.

42. Hai H, Tamori A, Thuy LTT, et al. Polymorphisms in MICA, but not in DEPDC5, HCP5 or PNPLA3, are associated with chronic hepatitis C-related hepatocellular carcinoma. Sci Rep. 2017;7:11912.

43. Mahdessian H, Taxiarchis A, Popov S, et al. TM6SF2 is a regulator of liver fat metabolism influencing triglyceride secretion and hepatic lipid droplet content. Proceedings of the National Academy of Sciences of the United States of America. 2014;111:8913-8.

44. Anstee QM, Seth D, Day CP. Genetic factors that affect risk of alcoholic and nonalcoholic fatty liver disease. Gastroenterology. 2016;150:1728-44. e7.

45. Youssef SS, Abd El Razek E, Mahdy RE, Seif S, El Kassas M. TM6SF2 and NCAN polymorphism impact on HCV in North African Egyptian patients. Journal of Bioscience and Applied Research. 2018;4:401-9. 46. Koo BK, Joo SK, Kim D, et al. Additive effects of PNPLA3 and TM6SF2 on the histological severity of nonalcoholic fatty liver disease. Journal of gastroenterology and hepatology. 2018;33:1277-85.

47. Tang S, Zhang J, Mei T-T, et al. Association of TM6SF2 rs58542926 T/C gene polymorphism with hepatocellular carcinoma: a meta-analysis. BMC cancer. 2019;19:1-9. 
48. Valenti L, Motta BM, Soardo G, et al. PNPLA3 I148M polymorphism, clinical presentation, and survival in patients with hepatocellular carcinoma. PloS one. 2013;8:e75982. 
Tables

Table 1: Demographic and clinical characteristics of HCV and HCC patients

\begin{tabular}{|c|c|c|c|c|c|}
\hline & & & $\begin{array}{c}\mathrm{HCV} \\
\mathrm{N}=144\end{array}$ & $\begin{array}{c}\mathrm{HCC} \\
\mathbf{N}=120\end{array}$ & P. value \\
\hline \multirow{6}{*}{ 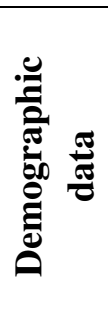 } & \multicolumn{2}{|c|}{ Age (years) } & $46.8 \pm 9.8$ & $61.5 \pm 7.2$ & $0.001 * *$ \\
\hline & \multirow[t]{2}{*}{ Gender } & Female & $71(49.3 \%)$ & $30(25.0 \%)$ & \multirow[t]{2}{*}{$0.001 * *$} \\
\hline & & Male & $73(50.7 \%)$ & $90(75.0 \%)$ & \\
\hline & \multicolumn{2}{|l|}{ Smoker } & $14(9.7 \%)$ & $34(28.3 \%)$ & $0.001 * *$ \\
\hline & \multicolumn{2}{|l|}{ Diabetes } & $26(18.1 \%)$ & $33(27.5 \%)$ & $0.04 *$ \\
\hline & \multicolumn{2}{|l|}{ BMI } & $28.7 \pm 4.0$ & $27.8 \pm 5.4$ & 0.1 \\
\hline \multirow{10}{*}{ 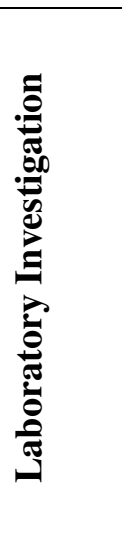 } & \multicolumn{2}{|l|}{ Hb } & $13.5 \pm 1.6$ & $12.9 \pm 2.0$ & $0.01 *$ \\
\hline & \multicolumn{2}{|l|}{ WBC } & $5.9 \pm 1.9$ & $6.7 \pm 2.8$ & 0.2 \\
\hline & \multicolumn{2}{|l|}{ Platelets } & $180.1 \pm 65.7$ & $159.4 \pm 71.9$ & $0.01 *$ \\
\hline & \multicolumn{2}{|l|}{ INR } & $1.0 \pm 0.1$ & $1.2 \pm 0.3$ & $0.001 * *$ \\
\hline & \multicolumn{2}{|l|}{ ALT } & $60.0(41.0-86.0)$ & $50.0(31.0-75.8)$ & $0.01 *$ \\
\hline & \multicolumn{2}{|l|}{$\overline{\text { AST }}$} & $61.0(43.0-87.0)$ & $58.5(35.0-80.5)$ & 0.2 \\
\hline & \multicolumn{2}{|l|}{ Alb } & $3.9 \pm 0.6$ & $3.6 \pm 0.6$ & $0.01 *$ \\
\hline & \multicolumn{2}{|l|}{ Bil.T } & $0.8(0.6-1.0)$ & $0.96(0.7-1.4)$ & $0.001 * *$ \\
\hline & \multicolumn{2}{|l|}{ AFP } & $6.0(2.8-12.6)$ & $61.2(9.6-242.1)$ & $0.001 * *$ \\
\hline & \multicolumn{2}{|l|}{ Crea. } & $0.9 \pm 0.5$ & $0.9 \pm 0.2$ & 0.5 \\
\hline \multirow{4}{*}{ 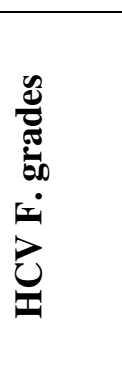 } & \multicolumn{2}{|l|}{ F1 } & $43(29.9 \%)$ & $29(24.2 \%)$ & 0.3 \\
\hline & \multicolumn{2}{|l|}{ F2 } & $27(18.8 \%)$ & $7(5.8 \%)$ & $0.01 *$ \\
\hline & \multicolumn{2}{|l|}{ F3 } & $42(29.2 \%)$ & $11(9.2 \%)$ & $0.001 * *$ \\
\hline & \multicolumn{2}{|l|}{ F4 } & $32(22.2 \%)$ & $73(60.8 \%)$ & $0.001 * *$ \\
\hline \multirow{4}{*}{ 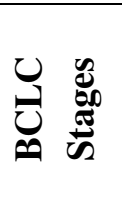 } & \multicolumn{2}{|l|}{ Early } & - & $56(46.7 \%)$ & - \\
\hline & \multicolumn{2}{|c|}{ Intermediate } & - & $44(36.7 \%)$ & - \\
\hline & \multicolumn{2}{|l|}{ Late } & - & $16(13.3 \%)$ & - \\
\hline & \multicolumn{2}{|c|}{ Advanced } & - & $4(3.3 \%)$ & - \\
\hline
\end{tabular}

Age, Body mass index (BMI), Hemoglobin (Hb), White blood cells (WBC), Platelets, International normalized ratio (INR), Albumin (Alb), Creatinine (Crea) are represented as Mean $\pm \mathrm{SD}$; the data were analyzed by student $\mathrm{t}$ test. While ALT, AST, Total bilirubin (Bil.T) and AFP are represented as Median with Interquartile range (25\% -75\%), the data were analyzed by Mann-whitney U test and Gender, Smoker, DM and HCV F. grades / BCLC Stages are represented as frequency and percent ; the data were analyzed by $\mathrm{X}^{2}$ test. $* \mathrm{P}$ value $\leq 0.05$ significant; **P value $\leq 0.01$ highly significant. 
Table 2: Genotype distribution of PNPLA3 rs738409 and TM6SF2 rs58542926 in HCV and HCC patients

\begin{tabular}{|c|c|c|c|c|c|c|c|}
\hline & & $\begin{array}{c}\text { HCV } \\
\mathrm{N}=144\end{array}$ & $\begin{array}{c}\text { HCC } \\
\mathrm{N}=120\end{array}$ & ${ }^{\text {aP. value }}$ & OR & 95\% C.I & ${ }^{b} P$. value \\
\hline \multirow{5}{*}{$\begin{array}{l}\text { PNPLA3 } \\
\text { rs738409 }\end{array}$} & $\mathrm{CC}$ & $72(50.0 \%)$ & $57(47.5 \%)$ & 0.6 & & 1(reference) & \\
\hline & $\mathbf{C G}$ & $58(40.3 \%)$ & $48(40.0 \%)$ & 0.9 & 1.045 & $0.624-1.753$ & 0.8 \\
\hline & GG & $14(9.7 \%)$ & $15(12.5 \%)$ & 0.4 & 1.353 & $0.604-3.033$ & 0.4 \\
\hline & C Allele & $202(0.701)$ & $162(0.675)$ & \multirow{2}{*}{0.6} & \multicolumn{3}{|c|}{1 (reference) } \\
\hline & G Allele & $86(0.299)$ & $78(0.325)$ & & 1.131 & $0.781-1.637$ & 0.5 \\
\hline \multirow{5}{*}{$\begin{array}{c}\text { TM6SF2 } \\
\text { rs58542926 }\end{array}$} & $\mathrm{CC}$ & $107(74.3 \%)$ & $84(70.0 \%)$ & 0.3 & & 1 (reference) & \\
\hline & CT & $35(24.3 \%)$ & $28(23.3 \%)$ & 0.8 & 1.019 & $0.574-1.808$ & 0.9 \\
\hline & TT & $2(1.4 \%)$ & $8(6.7 \%)$ & $0.03 *$ & 5.095 & $\begin{array}{l}1.054- \\
24.629\end{array}$ & $0.04 *$ \\
\hline & C Allele & $249(0.865)$ & $196(0.817)$ & \multirow{2}{*}{0.2} & \multicolumn{3}{|c|}{1 (reference) } \\
\hline & T Allele & $39(0.135)$ & $44(0.183)$ & & 1.433 & $0.896-2.293$ & 0.1 \\
\hline
\end{tabular}

OR: Odds Ratio; CI: Confidence Interval; ${ }^{*} \mathrm{P}$ value $\leq 0.05$ significant; $* * \mathrm{P}$ value $\leq 0.01$ highly significant.

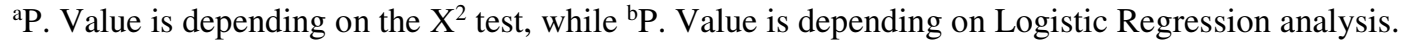

Table 3: association of HCC characteristics with genotype distribution of the studied genes 


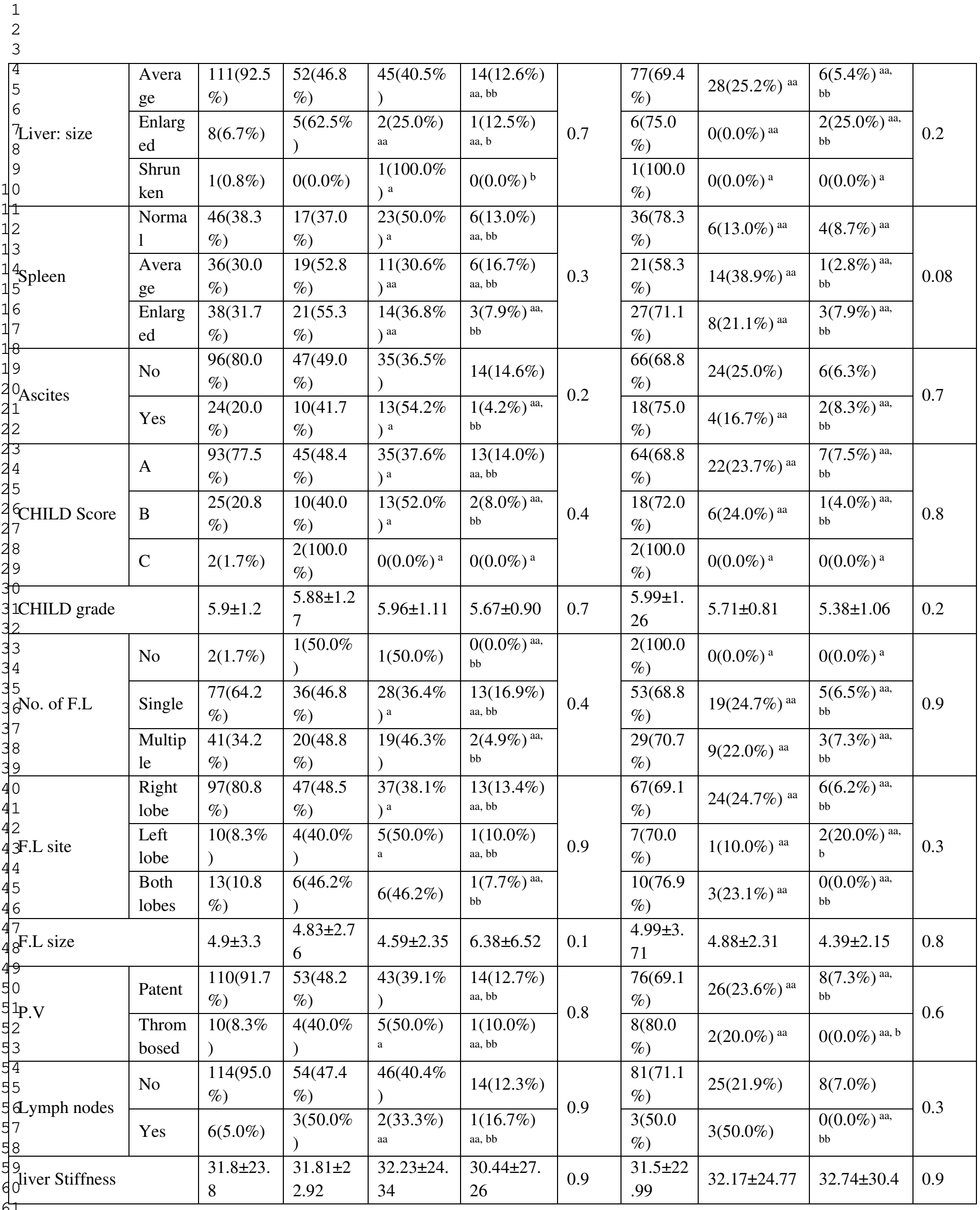




\begin{tabular}{|c|c|c|c|c|c|c|c|c|c|c|}
\hline \multicolumn{2}{|l|}{4 CAP } & $\begin{array}{l}223.4 \pm 7 \\
4.4\end{array}$ & $\begin{array}{l}238.05 \pm \\
70.53\end{array}$ & $\begin{array}{l}214.49 \pm 7 \\
7.87\end{array}$ & $\begin{array}{l}198.92 \pm 72 \\
.46\end{array}$ & 0.1 & $\begin{array}{l}218.5 \pm 7 \\
6.23\end{array}$ & $\begin{array}{l}231.52 \pm 61.5 \\
0\end{array}$ & $\begin{array}{l}236.75 \pm 98 . \\
16\end{array}$ & 0.6 \\
\hline \multirow{4}{*}{$\begin{array}{l}7 \\
8 \\
8 \text { Response to } \\
9 \\
0 \text { treatment } \\
1 \text { modified } \\
\text { 2RECIST } \\
3 \text { criteria } \\
4 \\
5\end{array}$} & $\begin{array}{l}\text { Compl } \\
\text { ete }\end{array}$ & $\begin{array}{l}73(60.8 \\
\%)\end{array}$ & $\begin{array}{l}32(43.8 \\
\%)\end{array}$ & $33(45.2 \%$ & $\begin{array}{l}8(11.0 \%) \\
\text { aa, bb }\end{array}$ & \multirow{4}{*}{$0.04 *$} & $\begin{array}{l}52(71.2 \\
\%)\end{array}$ & $15(20.5 \%)^{\text {aa }}$ & $\begin{array}{l}6(8.2 \%)^{\text {aa, }} \\
b b\end{array}$ & \multirow{4}{*}{$0.01 *$} \\
\hline & Partial & $\begin{array}{l}13(10.8 \\
\%)\end{array}$ & $8(61.5 \%$ & $\begin{array}{l}3(23.1 \%) \\
\text { aa }\end{array}$ & $\begin{array}{l}2(15.4 \%) \\
\text { aa, b }\end{array}$ & & $\begin{array}{l}10(76.9 \\
\%)\end{array}$ & $2(15.4 \%)^{\text {aa }}$ & $1(7.7 \%)^{\mathrm{aa}, \mathrm{b}}$ & \\
\hline & $\begin{array}{l}\text { Progre } \\
\text { ssive }\end{array}$ & $\begin{array}{l}13(10.8 \\
\%)\end{array}$ & $6(46.2 \%$ & $6(46.2 \%)$ & $\begin{array}{l}1(7.7 \%)^{\text {aa, }} \\
\text { bb }\end{array}$ & & $\begin{array}{l}4(30.8 \\
\%)\end{array}$ & $9(69.2 \%)^{\text {aа }}$ & $\begin{array}{l}0(0.0 \%)^{\text {aa, }} \\
\text { bb }\end{array}$ & \\
\hline & $\begin{array}{l}\text { Station } \\
\text { ary }\end{array}$ & $\begin{array}{l}16(13.3 \\
\%)\end{array}$ & $\begin{array}{l}9(56.3 \% \\
)\end{array}$ & $\begin{array}{l}5(31.3 \%) \\
\text { aa }\end{array}$ & $\begin{array}{l}2(12.5 \%) \\
\text { aa, bb }\end{array}$ & & $\begin{array}{l}14(87.5 \\
\%)\end{array}$ & $1(6.3 \%)^{\text {aa }}$ & $1(6.3 \%)^{\text {aa }}$ & \\
\hline \multirow{2}{*}{$\begin{array}{l}6 \\
7 \text { Clinical } \\
\text { odecompensati } \\
9 \text { on } \\
0\end{array}$} & No & $\begin{array}{l}99(82.5 \\
\%)\end{array}$ & $\begin{array}{l}47(47.5 \\
\%)\end{array}$ & $\begin{array}{l}38(38.4 \% \\
)\end{array}$ & $14(14.1 \%)$ & \multirow{2}{*}{0.4} & $\begin{array}{l}67(67.7 \\
\%)\end{array}$ & $24(24.2 \%)$ & $8(8.1 \%)$ & \multirow{2}{*}{0.3} \\
\hline & Yes & $\begin{array}{l}21(17.5 \\
\%)\end{array}$ & $\begin{array}{l}10(47.6 \\
\%)\end{array}$ & $\begin{array}{l}10(47.6 \% \\
)\end{array}$ & $\begin{array}{l}1(4.8 \%)^{\text {aa, }} \\
\mathrm{bb}\end{array}$ & & $\begin{array}{l}17(81.0 \\
\%)\end{array}$ & $4(19.0 \%)^{\mathrm{aa}}$ & $0(0.0 \%)$ & \\
\hline \multirow{2}{*}{$\begin{array}{l}2^{1} \text { Developed } \\
3^{\text {new lesions }} \\
4 \text { or not } \\
5\end{array}$} & No & $\begin{array}{l}113(94.2 \\
\%)\end{array}$ & $\begin{array}{l}54(47.8 \\
\%)\end{array}$ & $44(38.9 \%$ & $15(13.3 \%)$ & \multirow{2}{*}{0.5} & $\begin{array}{l}80(70.8 \\
\%)\end{array}$ & $26(23.0 \%)$ & $7(6.2 \%)$ & \multirow{2}{*}{0.6} \\
\hline & Yes & $7(5.8 \%)$ & $\begin{array}{l}3(42.9 \% \\
)\end{array}$ & $\begin{array}{l}4(57.1 \%) \\
a\end{array}$ & $\begin{array}{l}0(0.0 \%)^{a a}, \\
b b\end{array}$ & & $\begin{array}{l}4(57.1 \\
\%)\end{array}$ & $2(28.6 \%)^{\text {aa }}$ & $1(14.3 \%)^{\text {aa, }}$ & \\
\hline
\end{tabular}

Table 4: Association of BCLC staging with genotype distribution of the studied genes

\begin{tabular}{|c|c|c|c|c|c|c|c|}
\hline & & \multicolumn{4}{|c|}{ BCLC Stages } & \multirow[b]{2}{*}{ Total } & \multirow[b]{2}{*}{ P. value } \\
\hline & & $\begin{array}{l}\text { Early } \\
\mathrm{N}=56\end{array}$ & $\begin{array}{l}\text { Intermediate } \\
\mathrm{N}=44\end{array}$ & $\begin{array}{c}\text { Late } \\
\mathrm{N}=16\end{array}$ & $\begin{array}{c}\text { Advanced } \\
\mathrm{N}=4\end{array}$ & & \\
\hline \multirow{5}{*}{ PNPLA3 } & $\mathrm{CC}$ & $26(46.4 \%)$ & $21(47.7 \%)$ & $8(50.0 \%)$ & $2(50.0 \%)$ & $57(47.5 \%)$ & \multirow{3}{*}{0.8} \\
\hline & CG & $21(37.5 \%)$ & $19(43.2 \%)$ & $7(43.8 \%)$ & $1(25.0 \%)^{\text {aa }}$ & $48(40.0 \%)$ & \\
\hline & GG & $\begin{array}{c}9(16.1 \%)^{a a}, \\
b b\end{array}$ & $4(9.1 \%)^{a a, b b}$ & $1(6.3 \%)^{a a, b b}$ & $1(25.0 \%)^{\text {aa }}$ & $15(12.5 \%)$ & \\
\hline & C Allele & $73(0.652)$ & $61(0.693)$ & $23(0.719)$ & $5(0.625)$ & $162(0.675)$ & \multirow{2}{*}{0.7} \\
\hline & G Allele & $39(0.348)^{* *}$ & $27(0.307)^{* *}$ & $9(0.281)^{* *}$ & $3(0.375)^{* *}$ & $78(0.325)$ & \\
\hline \multirow{5}{*}{ TM6SF2 } & $\mathrm{CC}$ & $41(73.2 \%)$ & $32(72.7 \%)$ & $7(43.8 \%)$ & $4(100.0 \%)$ & $84(70.0 \%)$ & \multirow{3}{*}{0.2} \\
\hline & CT & $11(19.6 \%)^{\mathrm{aa}}$ & $9(20.5 \%)^{\text {aa }}$ & $8(50.0 \%)$ & $0(0.0 \%)^{\text {aa }}$ & $28(23.3 \%)$ & \\
\hline & TT & $4(7.1 \%)^{\text {aa, bb }}$ & $3(6.8 \%)^{a a, b b}$ & $1(6.3 \%)^{a a, b b}$ & $0(0.0 \%)^{\text {aa }}$ & $8(6.7 \%)$ & \\
\hline & C Allele & $93(0.830)$ & $73(0.830)$ & $22(0.688)$ & $8(1.000)$ & $196(0.817)$ & \multirow{2}{*}{$0.03 *$} \\
\hline & T Allele & $19(0.170)^{* *}$ & $15(0.170)^{* *}$ & $10(0.313)^{* *}$ & $0(0.000)$ & $44(0.183)$ & \\
\hline
\end{tabular}

Genotyping distributions are represented as frequency and percent; the data were analyzed by $\mathrm{X}^{2}$ test. ${ }^{\mathrm{a}} \mathrm{p}$ value is significantly different comparing with Wild type. ${ }^{b} \mathrm{p}$ value is significantly different comparing with Hetero type. ${ }^{*} \mathrm{p}$ value is significantly different comparing between Alleles . 
Table 5: Univariate and multivariate regression analysis of the risk factors of HCC

\begin{tabular}{|c|c|c|c|c|c|c|c|c|}
\hline & \multirow[b]{2}{*}{${ }^{1} \mathrm{OR}$} & \multicolumn{2}{|c|}{ 95\% C.I } & \multirow[b]{2}{*}{$\begin{array}{c}P . \\
\text { value }\end{array}$} & \multirow[b]{2}{*}{${ }^{2} \mathrm{OR}$} & \multicolumn{2}{|c|}{ 95\% C.I } & \multirow[b]{2}{*}{ P. value } \\
\hline & & $\begin{array}{l}\text { Lower } \\
\text { Bound }\end{array}$ & $\begin{array}{l}\text { Upper } \\
\text { Bound }\end{array}$ & & & $\begin{array}{l}\text { Lower } \\
\text { Bound }\end{array}$ & $\begin{array}{l}\text { Upper } \\
\text { Bound }\end{array}$ & \\
\hline Age & 1.277 & 1.202 & 1.357 & $0.001 * *$ & 1.251 & 1.170 & 1.338 & $0.001 * *$ \\
\hline $\begin{array}{c}\text { Gender } \\
\text { (Male) }\end{array}$ & 2.918 & 1.723 & 4.941 & $0.001^{* *}$ & 0.525 & 0.218 & 1.266 & 0.1 \\
\hline Smoker & 3.671 & 1.861 & 7.242 & $0.001 * *$ & 0.363 & 0.112 & 1.179 & 0.09 \\
\hline BMI & 0.959 & 0.909 & 1.011 & 0.1 & 0.710 & 0.253 & 1.996 & 0.5 \\
\hline DM & 1.721 & .960 & 3.086 & $0.05 *$ & 1.016 & 1.006 & 1.026 & $0.001 * *$ \\
\hline AFP & 1.021 & 1.013 & 1.029 & $0.001 * *$ & 0.247 & 0.019 & 3.176 & 0.1 \\
\hline
\end{tabular}

Body mass index (BMI), Diabetes mellitus (DM), and alpha-fetoprotein (AFP). OR; Odd Ratio, C.I; Confidence Interval, p-value calculated depend on logistic regression analysis. ${ }^{*}$ p. value $<0.05$ is significant, ${ }^{* *}$ p. value $<0.01$ is highly significant. ${ }^{1} \mathrm{OR}$ for univariate analysis, ${ }^{2} \mathrm{OR}$ for multivariate analysis.

Table 6: Factors associated with survival in HCC patients

\begin{tabular}{|c|c|c|c|c|c|}
\hline & & Dead F(\%) & $\begin{array}{l}\text { Median (95\% C.I) } \\
\text { of the Estimate } \\
\text { Survival Time }\end{array}$ & $\begin{array}{l}\text { Log Rank } \\
\text { (Mantel- } \\
\text { Cox) }\end{array}$ & P. value \\
\hline Gender & Female & $16(21.6 \%)$ & $262.0(218.8-305.1)$ & 1.183 & 0.3 \\
\hline & Male & $58(78.4 \%)$ & $335.0(247.9-422.1)$ & & \\
\hline Age & $<65$ & $55(74.3 \%)$ & $307.0(221.9-392.1)$ & 0.031 & 0.8 \\
\hline & $>65$ & $19(25.7 \%)$ & $350.0(202.1-497.9)$ & & \\
\hline Smoker & No & $53(71.6 \%)$ & $350.0(276.6-423.4)$ & 0.06 & 0.81 \\
\hline & Yes & $21(28.4 \%)$ & $306.0(129.6-482.4)$ & & \\
\hline Diabetes & No & $56(75.7 \%)$ & $367.0(279.0-455.0)$ & 3.957 & $0.04 *$ \\
\hline & Yes & $18(24.3 \%)$ & $241.0(95.5-386.5)$ & & \\
\hline BCLC Stages & Early & $32(43.2 \%)$ & 398.0(368.9-427.1) & 16.803 & $0.001 * *$ \\
\hline & Intermediate & $27(36.5 \%)$ & $271.0(174.3-367.7)$ & & \\
\hline & Advanced & $3(4.1 \%)$ & $187.0(210-379.0)$ & & \\
\hline & Late & $12(16.2 \%)$ & $226.0(47.8-404.2)$ & & \\
\hline ECOG & 0 & $44(59.5 \%)$ & $367.0(283.6-450.4)$ & 13.277 & $0.004 * *$ \\
\hline Performance status & 1 & $26(35.1 \%)$ & 249.0(141.6- 356.4) & & \\
\hline & 2 & $3(4.1 \%)$ & $148.0(136.8-159.2)$ & & \\
\hline & 3 & $1(1.4 \%)$ & $67.0(67.0-67.0)$ & & \\
\hline Child-Pugh Score & A & $52(70.3 \%)$ & $369.0(265.4-472.6)$ & 0.25 & 0.9 \\
\hline & B & $20(27.0 \%)$ & 214.0(146.1-281.9) & & \\
\hline
\end{tabular}




\begin{tabular}{|c|c|c|c|c|c|}
\hline & $\mathrm{C}$ & $2(2.7 \%)$ & $141.0(120.0-141.0)$ & & \\
\hline \multirow{5}{*}{$\begin{array}{l}\text { Response to to } \\
\text { treatment modified } \\
\text { RECIST criteria }\end{array}$} & Not treated & $1(1.4 \%)$ & $57.0(57.0-57.0)$ & \multirow[t]{5}{*}{22.281} & \multirow[t]{5}{*}{$0.001 * *$} \\
\hline & Stationary & $14(18.9 \%)$ & $208.0(182.3-233.7)$ & & \\
\hline & Partial response & $7(9.5 \%)$ & $306.0(193.1-418.9)$ & & \\
\hline & $\begin{array}{l}\text { Complete } \\
\text { response }\end{array}$ & $41(55.4 \%)$ & $394.0(371.0-417.0)$ & & \\
\hline & $\begin{array}{l}\text { Progressive } \\
\text { disease }\end{array}$ & $11(14.9 \%)$ & $226.0(91.1-360.9)$ & & \\
\hline \multirow{2}{*}{$\begin{array}{l}\text { Liver Stiffness } \\
\text { cutoff }=9.5\end{array}$} & $<9.5$ & $5(9.6 \%)$ & $384.0(25.4-742.6)$ & \multirow[t]{2}{*}{0.003} & \multirow[t]{2}{*}{0.9} \\
\hline & $>9.5$ & $47(90.4 \%)$ & $307.0(221.0-393.0)$ & & \\
\hline \multirow{2}{*}{$\begin{array}{l}\text { Liver Stiffness } \\
\text { cutoff }=12.5\end{array}$} & $<12.5$ & $9(17.3 \%)$ & $394.0(364.8-423.2)$ & \multirow[t]{2}{*}{0.01} & \multirow[t]{2}{*}{0.9} \\
\hline & $>12.5$ & $43(82.7 \%)$ & $306.0(241.8-370.2)$ & & \\
\hline \multirow[t]{3}{*}{ PNPLA3 } & $\mathrm{CC}$ & $37(50.0 \%)$ & $306.0(229.7-382.3)$ & \multirow[t]{3}{*}{1.963} & \multirow[t]{3}{*}{0.4} \\
\hline & $\overline{\mathrm{CG}}$ & $29(39.2 \%)$ & $307.0(196.2-417.8)$ & & \\
\hline & $\overline{\mathrm{GG}}$ & $8(10.8 \%)$ & $394.0(345.5-442.5)$ & & \\
\hline \multirow[t]{3}{*}{ TM6SF2 } & $\mathrm{CC}$ & $56(75.7 \%)$ & $312.0(235.0-389.0)$ & \multirow[t]{3}{*}{2.104} & \multirow[t]{3}{*}{0.3} \\
\hline & $\mathrm{CT}$ & $15(20.3 \%)$ & $248.0(130.6-365.4)$ & & \\
\hline & $\overline{T T}$ & $3(4.1 \%)$ & $426.0(378.0-474.0)$ & & \\
\hline
\end{tabular}

C.I: Confidence Interval, the data were analyzed by Kaplan-Meier test, $*$ p. value $<0.05$ is significant, $* *$ p. value $<0.01$ is highly significant

\section{Figures}
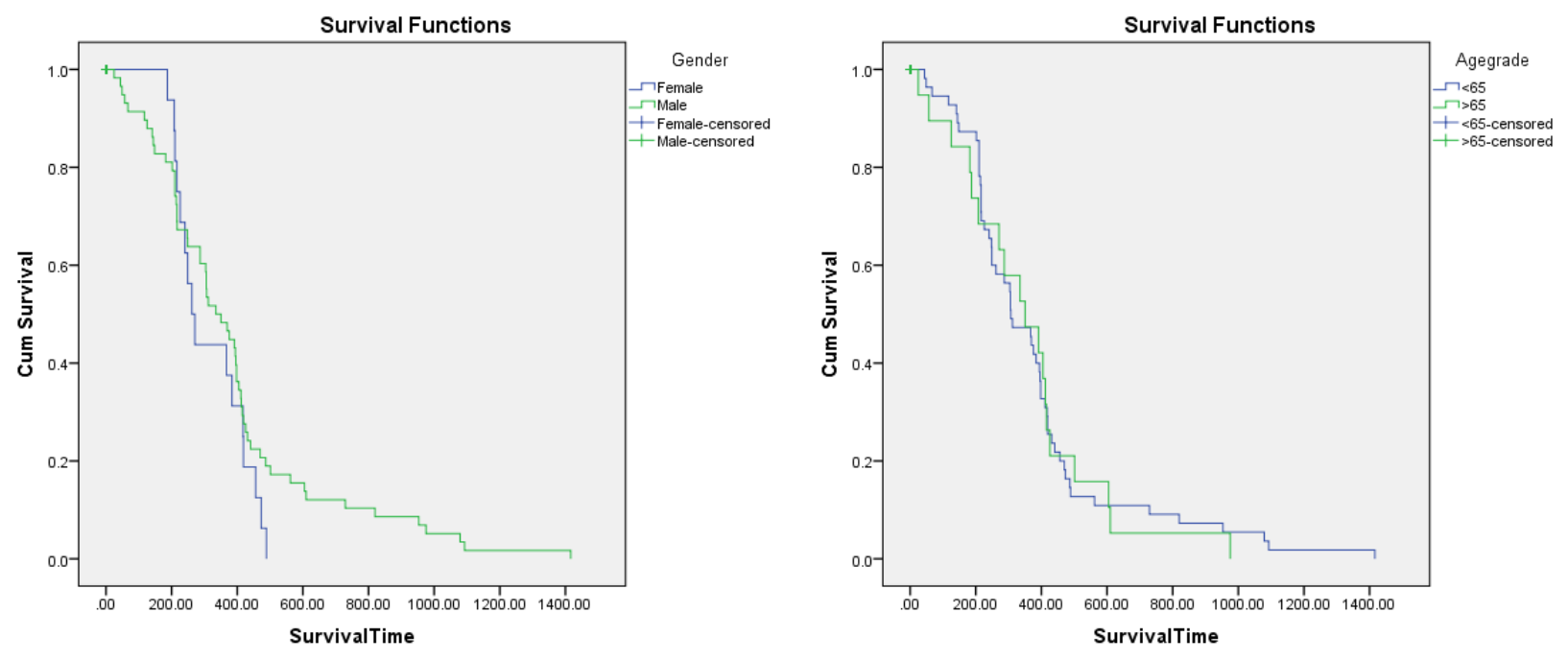

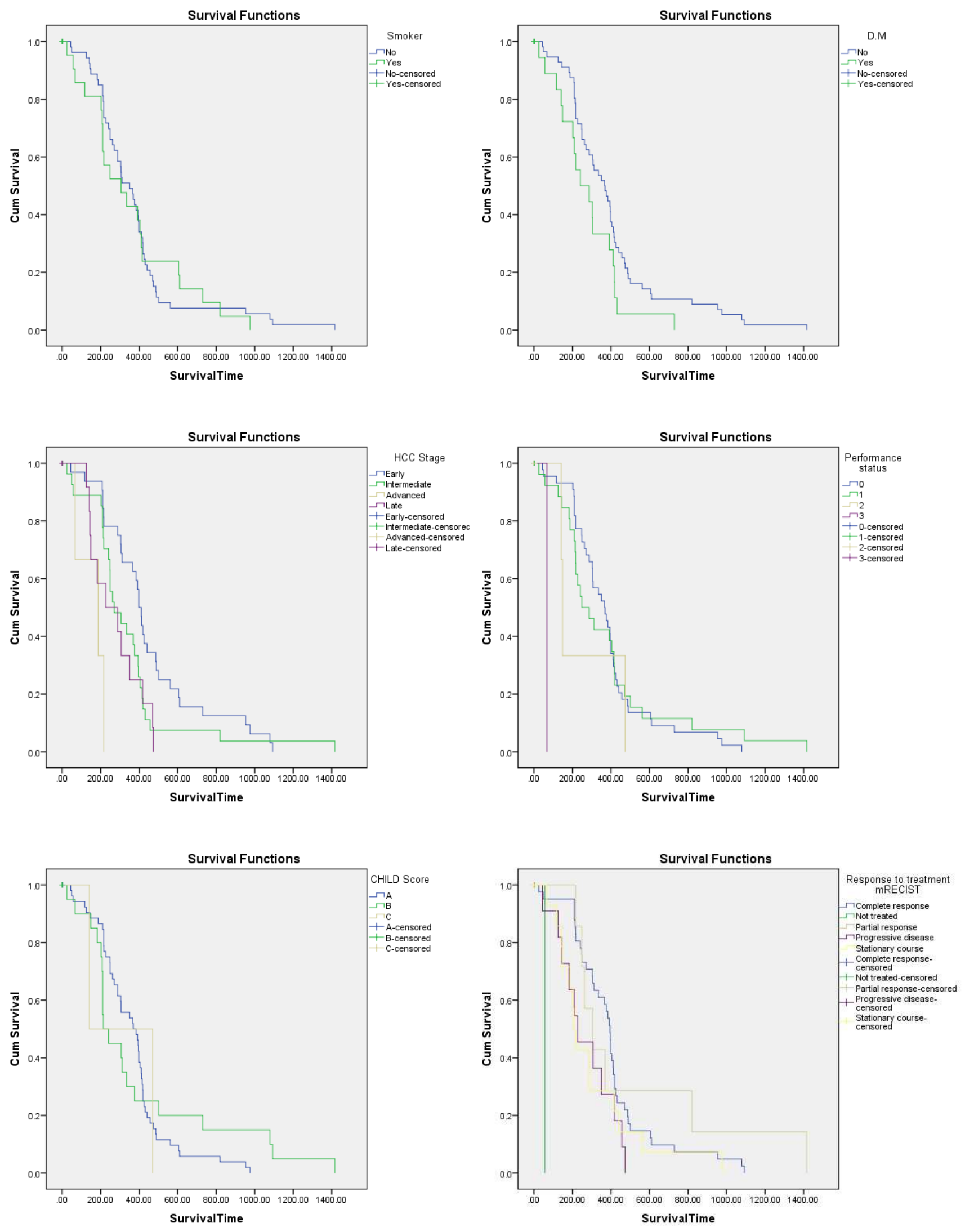

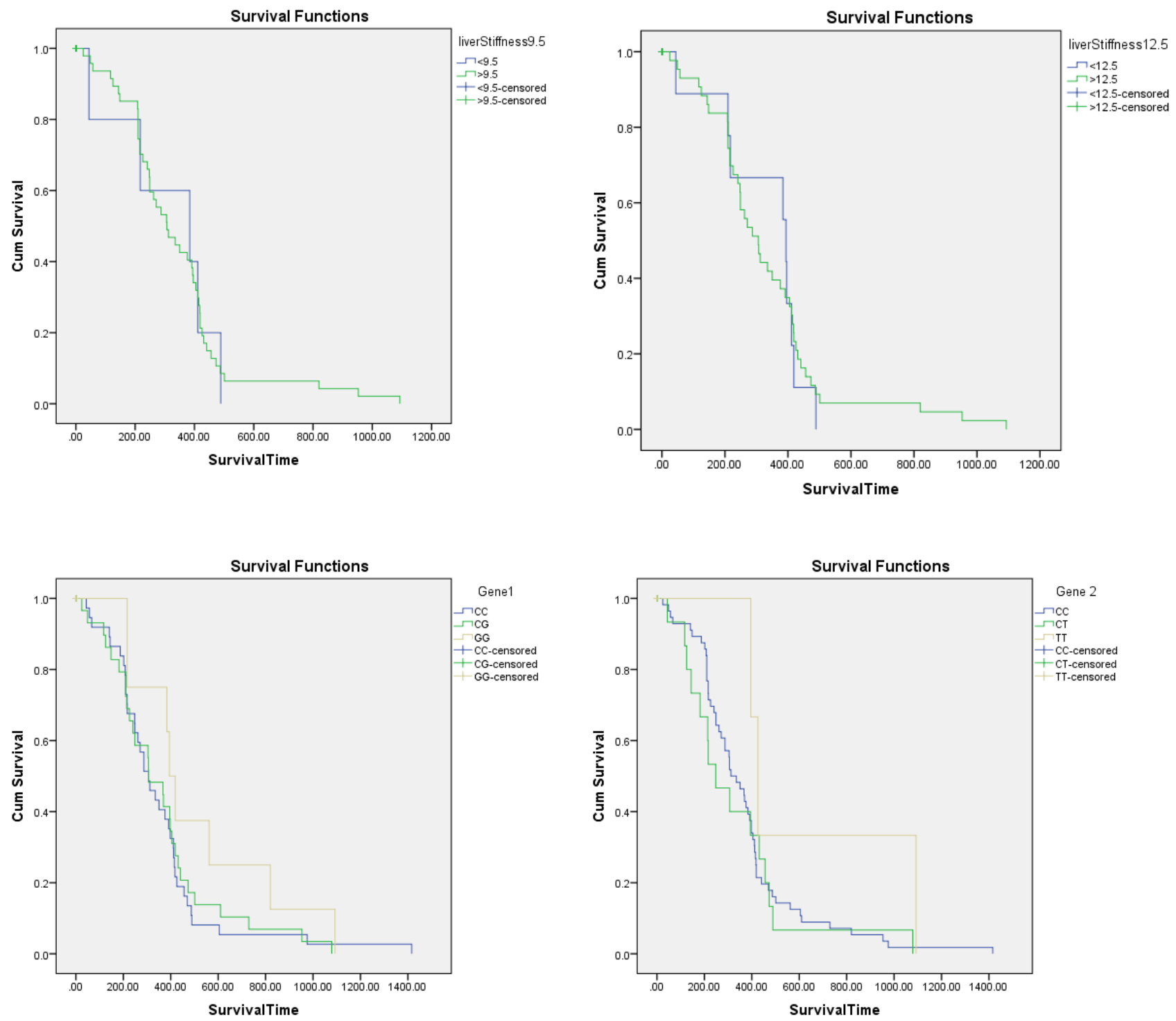

Fig. 1: Survival curve among the studied parameters; Gene1: PNPLA3, gene 2: TM6SF2 
Figures
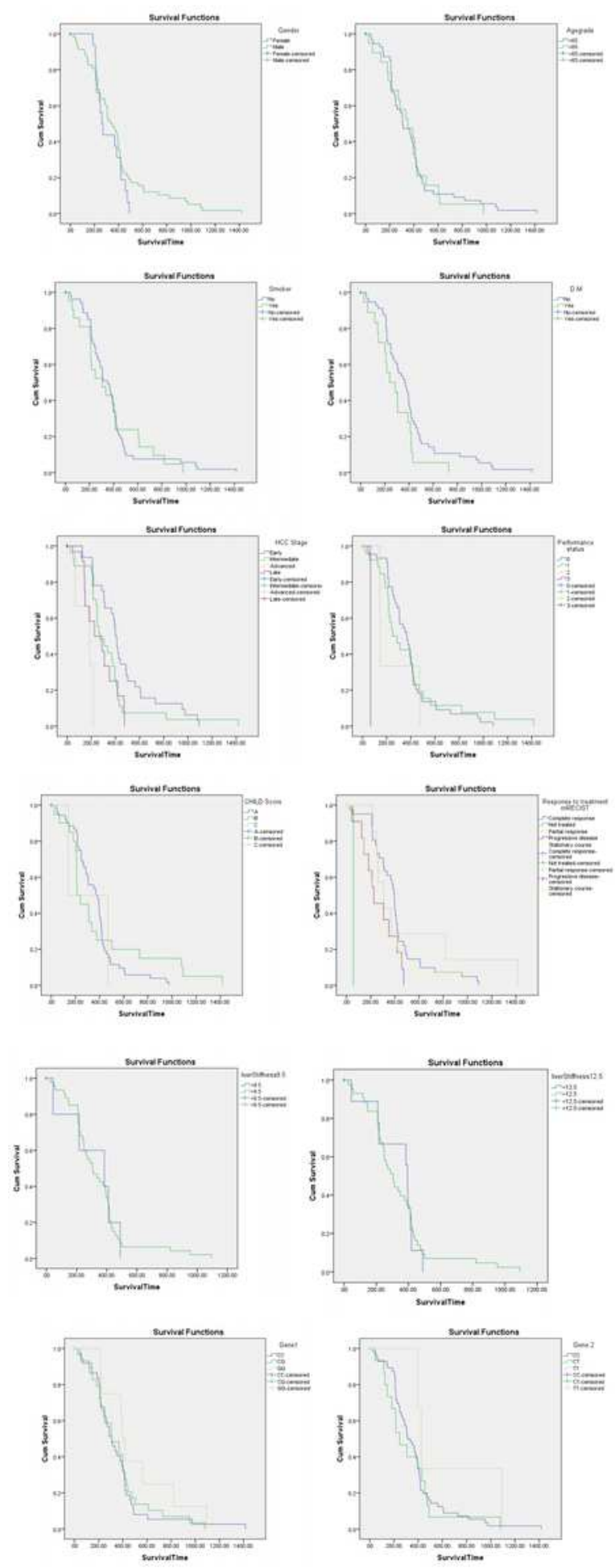

Figure 1

Survival curve among the studied parameters; Gene1: PNPLA3, gene 2: TM6SF2 